\title{
A Recyclable, Immobilized Analogue of Benzotetramisole for Catalytic Enantioselective Domino Michael Addition/Cyclization Reactions in Batch and Flow
}

\author{
Javier Izquierdo $^{\dagger}$ and Miquel A. Pericàs* ${ }^{*} \dagger$, \\ ${ }^{\dagger}$ Institute of Chemical Research of Catalonia (ICIQ), The Barcelona Institute of Science and Technology, Avinguda Països Catalans \\ 16, 43007 Tarragona, Spain \\ ${ }^{*}$ Departament de Química Orgànica, Universitat de Barcelona (UB), 08028 Barcelona, Spain
}

Supporting Information

ABSTRACT: A polystyrene-supported, enantiopure benzotetramisole (BTM) analogue (5) has been synthesized from $(2 S, 3 S)$-phenylglycidol through a five-step sequence involving a copper-catalyzed alkyne azide cycloaddition (CuAAC) reaction as the final, immobilization step. The functional resin $5\left(f=0.9 \mathrm{mmol} \mathrm{g}^{-1}\right)$ has been successfully used as a highly active and enantioselective catalyst in the domino Michael addition/cyclization reaction of in situ activated arylacetic acids (7) with chalcone-type tosylimines (6), leading to dihydropyridinones 8 (17 examples) to afford the products with excellent yields and very high enantioselectivity (mean ee 97.4\%). The deactivation of 5 by species present during the catalytic process has been studied, and pivaloyl chloride (required for the activation of the arylacetic acid) has been identified as the main source of deactivation. A simple experimental protocol taking this fact into account has allowed the multiple recycling of $\mathbf{5}$ with only a marginal decrease in catalytic activity and the implementation of a continuous flow process where the activation of phenylacetic acid (residence time 14.2 min), the asymmetric domino Michael addition/cyclization reaction (residence time $7.5 \mathrm{~min}$ ), and aqueous workup are performed sequentially, delivering the dihydropyridinone product as a clean dichloromethane solution $(0.54 \mathrm{mmol}$ catalyst sample; $11 \mathrm{~h}$ operation; $8 \mathrm{a}(4.44 \mathrm{~g},>99.9 \%$ ee)). The supported catalyst 5 has also been used in a new domino Michael addition/cyclization reaction involving saccharin-derived tosylimines 9 as electrophiles, leading to 8,9-dihydro-7H-benzo[4,5]isothiazolo[2,3a]pyridin-7-one 5,5-dioxides 10 (8 examples) in high isolated yields and diastereoselectivities and excellent enantioselectivities (mean ee $98 \%)$. A single sample of $5(0.5 \mathrm{~g}, 0.45 \mathrm{mmol})$ has been used for the sequential preparation in batch of a library of 7 different derivatives 10 at the gram scale (ca. $10 \mathrm{~g}$, accumulated TON $=51$ ), the whole process being performed without any column chromatographic purification. The increased diastereoselectivity recorded with $\mathbf{5}$ in reactions involving sterically congested arylacetic acids (with respect to homogeneous BTM) has been rationalized through the occurrence of steric interactions between the sulfonylimine and the linker plus support catalyst fragments leading to additional destabilization of the transition state leading to the minor, cis diastereomer of products $8 / 10$.

KEYWORDS: asymmetric catalysis, isothioureas, polystyrene-supported catalysts, domino reactions, continuous flow

\section{INTRODUCTION}

Organocatalysts present inherent practical advantages, such as tolerance to moisture or oxygen, high availability (as many organocatalysts are derived from abundant natural products), and low or no toxicity. In addition, organocatalysis provides simple and effective pathways for transformations hardly achievable by other methodologies. ${ }^{1}$ For all these reasons, organocatalysis is called upon to play an increasingly important role in key industrial sectors, including the pharmaceutical industry. When this new perspective is considered, aspects of organocatalysis such as reduced catalyst loadings, easy recovery, and the possibility of repeated recycling come to the front not only for sustainability but also for economic reasons.
The use of chiral immobilized catalysts by the synthetic community is experiencing a continued increase due to the significant advantages provided by this strategy: straightforward catalyst separation and recovery can be achieved by a simple filtration (polymer matrices) or magnetic decantation (magnetic nanoparticles) with suppression of wasteful workup stages. In addition, sufficiently active immobilized catalytic systems allow the implementation of a flow process for the continuous production of chiral enantiopure compounds. ${ }^{2}$

Received: September 23, 2015

Revised: December 2, 2015

Published: December 4, 2015 
Enolate addition to a variety of electrophiles has become one of the most employed methodologies for the formation of $\mathrm{C}-\mathrm{C}$ bonds. ${ }^{3}$ Thus, new methodologies for asymmetric enolate generation are highly desirable. In this domain, methodologies involving the use of transition-metal catalysts have been documented for years, ${ }^{4}$ but Lewis base type catalysts such as secondary amines, ${ }^{5}$ isothioureas, ${ }^{6}$ cinchona alkaloid derivatives, $^{7}$ and N-heterocyclic carbenes (NHCs) ${ }^{8}$ have emerged as suitable precursors for the generation of chiral enolates under less demanding experimental conditions. In particular, the generation of chiral ammonium enolates ${ }^{9}$ as highly versatile organocatalytic intermediates has been successfully achieved by in situ activation of carboxylic acids, avoiding the tedious task of isolation and purification of these intermediates. ${ }^{10}$

Within this area, benzotetramisole (BTM), an amidine-based catalyst originally introduced by Birman, ${ }^{11}$ has been successfully employed as a nonenzymatic acyl transfer isothiourea catalyst for kinetic resolutions and desymmetrization processes. ${ }^{12}$ BTM was subsequently employed by Romo ${ }^{13}$ as a precursor of ammonium enolates in a highly stereoselective intramolecular domino process known as nucleophile catalyzed aldollactonization (NCAL), while Smith has expanded its use to a variety of processes. ${ }^{14}$ To the best of our knowledge, the use of supported isothioureas as organocatalysts has not yet been reported in the chemical literature.

Dihydropyridones and 1-dihydro- $1 \mathrm{H}$-benzothiazolopyridines are recognized structures which can be found in cores of many biologically active natural products and drugs with widespread pharmaceutical antitumoral and antibacterial activities. ${ }^{15}$ These motifs have been synthesized traditionally through the azaDiels-Alder reaction, ${ }^{16}$ but there are few asymmetric methodologies to promote this transformation. While the first enantioselective methodology leading to these substances was a metal-catalyzed reaction developed by Carretero, ${ }^{17}$ several organocatalytic approaches have been reported in the last few years involving the Jørgensen-Hayashi catalyst, ${ }^{18}$ N-heterocyclic carbenes, ${ }^{19}$ or isothioureas. ${ }^{14 \mathrm{~b}, \mathrm{i}}$

Within our research program aiming at developing new immobilized catalysts with improved characteristics over their homogeneous counterparts, we considered that BTM, for its widespread use, was an optimal candidate for immobilization. An analysis of the BTM structure (Figure 1) suggested that

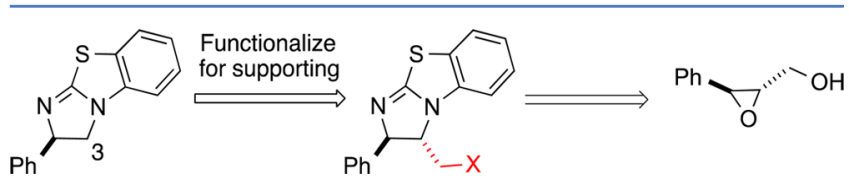

Figure 1. Design and retrosynthetic analysis of BTM derivatives suitable for immobilization.

position 3 could be ideal for immobilization purposes, since an additional substituent at this carbon would occupy a spatially remote position with respect to the catalytic site (the thiourea moiety). The retrosynthetic introduction of a functional carbon atom in this position ultimately leads to phenylglycidol, a material readily available in enantiopure form at the multigram scale by catalytic asymmetric Sharpless epoxidation, ${ }^{20,21}$ as the chiral educt for the preparation of the immobilized BTM analogue. Interestingly, this approach could be adapted for diversity and fine tuning, given the broad variety of arylglycidols available in enantiopure form by Sharpless epoxidation.
We wish to report the preparation according to this design of the PS-supported BTM derivative 5, involving the use of a copper-catalyzed alkyne azide cycloaddition (CuAAC) reaction $^{22}$ (click chemistry ${ }^{23}$ ) as the tool for the immobilization of the properly functionalized intermediate 4 onto azidomethyl polystyrene, and the use of $\mathbf{5}$ as a highly efficient organocatalyst for the domino Michael addition/cyclization reactions of arylacetic acids with chalcone or saccharin-derived tosyl imines. $^{24}$

\section{RESULTS AND DISCUSSION}

The synthesis of the supported catalyst $\mathbf{5}$ started from enantiopure ( $>99.5 \%$ ee) alkynyl epoxy ether $1^{25}$ which was regioselectively ring-opened with ammonia to afford amino alcohol 2. ${ }^{25 a, 26}$ Then, stoichiometric amounts of amino alcohol 2 and chlorobenzothiazole were heated in a pressure tube to afford the propargylated benzothiazole 3 , which contains all the structural elements for isothiourea synthesis and immobilization. Cyclization to isothiourea $\mathbf{4}$ was achieved by a two-step protocol involving mesylation of the secondary hydroxy group followed by intramolecular $S_{N} 2$ displacement by the nucleophilic benzothiazole nitrogen of compound 3 . The absolute configuration of compound 4 was confirmed by X-ray difraction. ${ }^{27}$ Finally, a CuAAC reaction with azidomethyl polystyrene afforded the supported BTM analogue 5 with high immobilization yield $\left(98 \% ; f=0.9 \mathrm{mmol} \mathrm{g}^{-1}\right)$ (Scheme 1). Full experimental details for the preparation of $\mathbf{5}$ are given in the Supporting Information.

As an initial assessment of the performance of the immobilized isothiourea 5, we decided to test it as a catalyst in the synthesis of dihydropyridinones previously reported by Smith et al. ${ }^{14 \mathrm{~b}}$ (Table 1). Following the reported protocol, phenylacetic acid (7a), $i$ - $\operatorname{Pr}_{2} \mathrm{NEt}$, and pivaloyl chloride ( 2 equiv each) were mixed together before addition to a mixture of tosylimine $\mathbf{6 a}$ and supported-BTM 5, followed by a second addition of base. Gratifyingly, full conversion into dihydropyridinone 8a was observed in only $2 \mathrm{~h}$, the product being obtained with excellent enantioselectivity (entry 1). Modification of the activating reagent (entry 2), work at higher concentration (entry 3), or a decrease in the amount of the anhydride precursors (entry 4) led to lower conversion. Greener solvents, such as EtOAc (entry 5) and 2-methyltetrahydrofuran (2-Me-THF, entry 6), were also tested, but conversion drastically decreased in these media. From a practical perspective, we found that preactivation time was unnecessary for the efficient formation of the mixed anhydride and that this key intermediate could be formed efficiently in a one-pot manner, with all the reagents added simultaneously. This simplified procedure allowed reducing the reaction time to $2 \mathrm{~h}$ and the amount of base to only 2 equiv (entry 7 ). The use of phenylacetyl chloride was also tested in the reaction (entry 8 ), but this led to significantly lower conversion. Although very high enantioselectivity was recorded under these conditions, the catalyst was deactivated after the reaction (see the Supporting Information). This observation led us to reconsider the optimal amount of pivaloyl chloride to be used in the reaction. After some experimentation, we found that reducing the amount of this reagent to 1.75 equiv was beneficial for preserving the catalytic activity of $\mathbf{5}$, and this modification was adapted for future work under the conditions of entry 7 . At this point, we decided to compare the performance of 5 with that of unsubstituted benzotetramisole (BTM) in the reaction of $\mathbf{6 a}$ with $7 \mathbf{a}$ under the previously optimized reaction conditions 
Scheme 1. Synthesis of the PS-Supported BTM Analogue 5

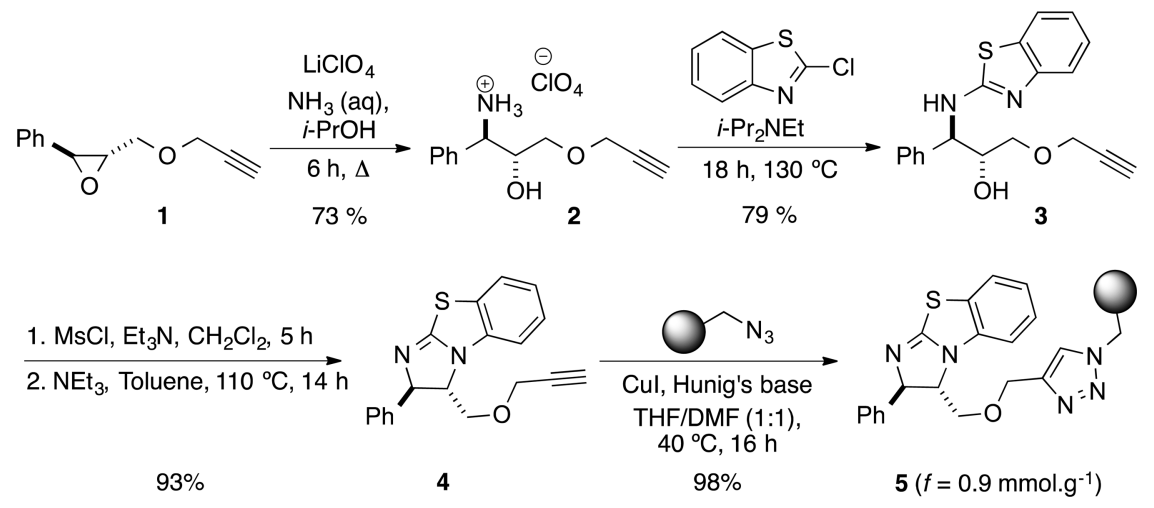

Table 1. Optimization of the Tandem Michael Addition/ Cyclization Reaction of Phenylacetic Acid 7a and Tosylimine 6a
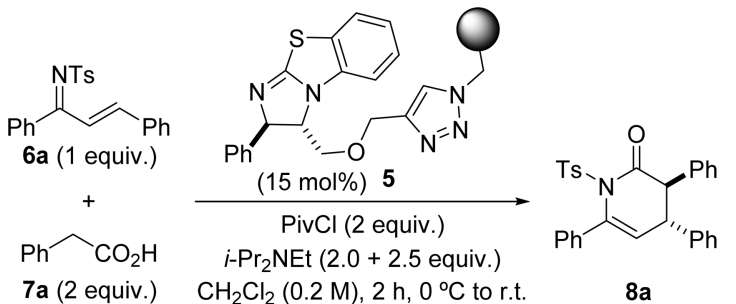

a (2 equiv.)

$\mathrm{CH}_{2} \mathrm{Cl}_{2}(0.2 \mathrm{M}), 2 \mathrm{~h}, 0^{\circ} \mathrm{C}$ to r.t.

$8 \mathbf{a}$

\begin{tabular}{|c|c|c|c|}
\hline entry & modification of standard conditions & $\begin{array}{c}\text { conversion } \\
(\%)^{a}\end{array}$ & $\mathrm{ee}^{b}$ \\
\hline 1 & standard conditions ${ }^{c}$ & $>95$ & 96 \\
\hline 2 & $\mathrm{TsCl}$ instead of $\mathrm{PivCl}$ & 62 & \\
\hline 3 & $\mathrm{CH}_{2} \mathrm{Cl}_{2}(0.5 \mathrm{M})$ instead of $\mathrm{CH}_{2} \mathrm{Cl}_{2}(0.2 \mathrm{M})$ & 60 & \\
\hline 4 & 1.2 equiv of $\mathrm{PivCl}$ and $\mathrm{BnCOOH}$ & 47 & \\
\hline 5 & EtOAc instead of $\mathrm{CH}_{2} \mathrm{Cl}_{2}$ & 26 & \\
\hline 6 & 2-Me-THF instead of $\mathrm{CH}_{2} \mathrm{Cl}_{2}$ & 9 & \\
\hline 7 & $\begin{array}{l}2 \text { equiv of } \mathrm{i}-\mathrm{Pr}_{2} \mathrm{NEt} \text { instead of } 2.0+2.5 \\
\text { equiv }\end{array}$ & $>95^{e}$ & 97 \\
\hline 8 & $\mathrm{BnCOCl}$ instead of $\mathrm{PivCl}$ and $\mathrm{BnCOOH}$ & 43 & 99 \\
\hline 9 & as in entry $7 f_{;}^{f}$ but with BTM as the catalyst & $74^{g}$ & 98 \\
\hline
\end{tabular}

${ }^{a}$ By ${ }^{1} \mathrm{H}$ NMR. ${ }^{b}$ By chiral HPLC. ${ }^{c}$ Phenylacetic acid $7 \mathbf{a}$ (2 equiv) was preactivated with pivaloyl chloride and i- $\mathrm{Pr}_{2} \mathrm{NEt}$ (2 equiv each) and stirred at $0{ }^{\circ} \mathrm{C}$ for $15 \mathrm{~min}$ before addition to a mixture of PS-BTM 5 and tosylimine $6 \mathbf{a} .{ }^{d}$ No preactivation for phenylacetic acid $7 \mathbf{a} .{ }^{e} 79 \%$ isolated yield and $>98: 2 \mathrm{dr}$ with 1.75 equiv of $\mathrm{PivCl}$, isolated yield was $83 \%$, with $98.5: 1.5 \mathrm{dr}$ and $99 \%$ ee. ${ }^{f_{1.75}}$ equiv of $\mathrm{PivCl} .{ }^{g} 68 \%$ isolated yield and 82:18 dr.

(entry 7, with 1.75 equiv of PivCl). As can be seen (entry 9), catalyst $\mathbf{5}$ is clearly advantageous under these conditions, leading to notably improved diastereoselectivity and isolated yield.

The scope of the tandem Michael addition/cyclization reaction was explored by using diverse arylacetic acids 7 or chalcone-derived tosylimines 6 (Table 2), the corresponding dihydropyridinones $\mathbf{8 a}-\mathbf{q}$ being obtained in excellent yield and enantioselectivity for the different substituent types tested, as reported for BTM. ${ }^{14 \mathrm{~b}}$ Homogenous BTM has demonstrated to be sensitive to ortho-substituted arylacetic acids, displaying low diastereoselectivity for these kinds of substrates. Interestingly, this limitation is completely suppressed with the immobilized BTM analogue 5, which rendered the products featuring this substitution pattern in very good diastereomeric ratio and isolated yields $(\mathbf{8 b}, \mathbf{c})$. This behavior indicates that the substituent at C-3 on the BTM structure, introduced to allow immobilization, further destabilizes the transition state leading to the minor cis diastereomer during the addition step (see Figure 3 for a pictorial representation of these destabilizing interactions in an analogous case). In contrast with our results, another BTM derivative reported in the literature featuring a similar trans-substitution pattern was demonstrated to be less active than unsubstituted BTM. ${ }^{28}$

The reaction was also tested with carboxylic acids of other structural types. Not unexpectedly, arylacetic acids with $\alpha$ substitution or aliphatic carboxylic acids did not yield any product in the reaction. $^{29}$

Once the high catalytic activity and the versatility of $\mathbf{5}$ in domino Michael addition/cyclization reactions had been established, the robustness of the catalyst in this benchmark reaction was tested. To this end, a study of the recyclability of the PS-supported BTM analogue 5 was performed (Table 3). The experiments were carried out by addition of the reagents and freshly distilled solvent to a sample of $\mathbf{5}$. After $2 \mathrm{~h}$, the reaction mixture was separated from the catalytic resin by simple filtration, and the resin was washed with dichloromethane before reuse. Gratifyingly, catalyst 5 showed high activity in six consecutive cycles, no significant decrease of catalytic activity being recorded. It is worth noting that the enantioselectivity of the process was kept constant (97\% ee) over the six reaction cycles. To get further insight into the behavior of $\mathbf{5}$ during recycling, the kinetic profile of two consecutive, identical experiments was followed by NMR. It could be established in this manner that the reaction profiles are superimposable, thus discarding the possibility of deactivation processes obscured by the use of excess catalyst (see the Supporting Information).

Encouraged by these promising results of recyclability, the possibility of implementing a continuous flow protocol comprising both processes, i.e. the preactivation of the carboxylic acid reactant and the organocatalytic domino transformation, taking place sequentially in the same setup was envisaged. Although challenging in principle, a protocol with these characteristics would realize all the simplification potential and practical advantages of the flow paradigm with respect to classical batch processing for the considered transformation.

The required flow setup (Figure 2) is described in detail in the Supporting Information. The noncatalytic formation of the mixed anhydride should take place in a simple tubular reactor with length optimized for full conversion, and the mixed anhydride would then mix with the preformed tosyl imine at 
Table 2. Domino Michael Addition/Cyclization of in Situ Activated Arylacetic Acids 7 with Chalcone-Derived Tosylimines 6
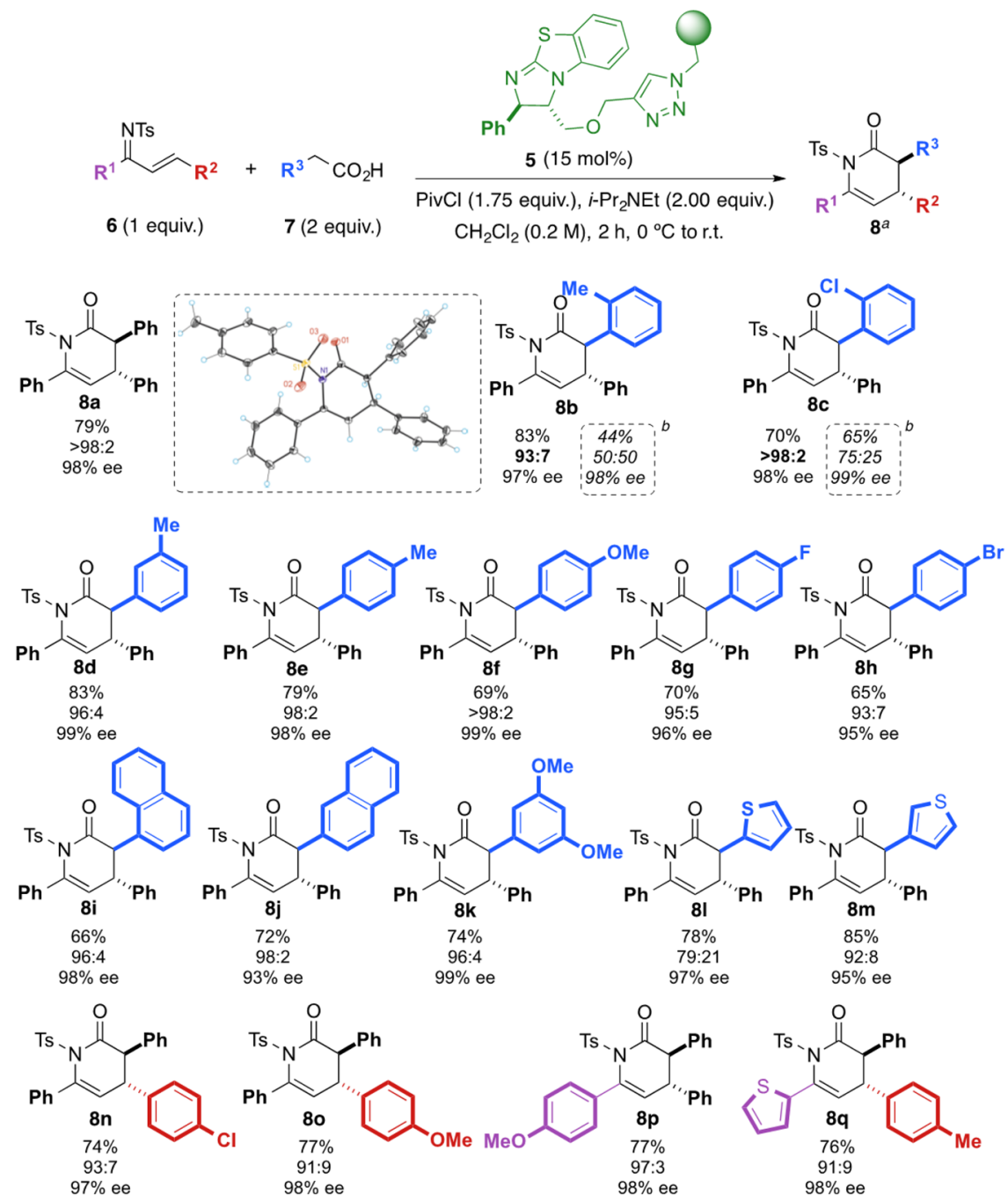

${ }^{a}$ Values beneath each structure are as follows: first line, isolated yield after column chromatography; second line, diastereomeric ratio determined by ${ }^{1} \mathrm{H}$ NMR; third line, enantiomeric excess determined by chiral HPLC. ${ }^{b}$ Results obtained with homogeneous BTM. ${ }^{14 \mathrm{~b}}$

Table 3. Recycling of the PS-BTM Analogue 5 in the Domino Michael Addition/Cyclization Reaction of Chalcone-Derived Tosylimine $6 a$ and Phenylacetic Acid $7 a^{a}$

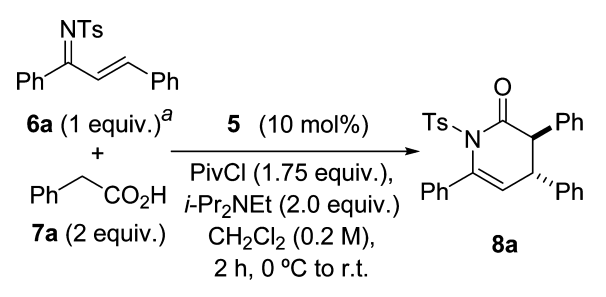

\begin{tabular}{|ccc|}
\hline cycle & conversion $(\%)^{b}$ & ee $(\%)^{c}$ \\
\hline 1 & 87 & 97 \\
2 & 85 & 97 \\
3 & 87 & 97 \\
4 & 85 & 97 \\
5 & 83 & 97 \\
6 & 83 & 97 \\
\hline
\end{tabular}

${ }^{a}$ Reactions performed at $0.15 \mathrm{mmol}$ scale. ${ }^{b} \mathrm{By}{ }^{1} \mathrm{H}$ NMR. ${ }^{c} \mathrm{By}$ chiral HPLC.

the entrance of a catalytic reactor containing a suitable amount of PS-supported BTM analogue 5. In-line IR analysis at the reactor outlet should allow manipulation of the different flow rates (mixed anhydride and tosylimine) for the achievement of the desired conversion level. As an additional requirement, the amount of deactivating pivaloyl chloride entering in contact with the catalytic resin should be minimized. In order to perform continuous product isolation, water would be added at a controlled flow rate to the reaction output (to allow extraction of pivalic acid and $i-\mathrm{Pr}_{2} \mathrm{NEt}$ ), and phase separation would be performed in line. For the implementation of the flow process, resin $5(600 \mathrm{mg}, 0.54 \mathrm{mmol})$ was swollen with dichloromethane in the size-adjustable, medium-pressure chromatography column used as a reactor, and dichloromethane solutions of tosylimine $\mathbf{6 a}$ and the mixed phenylacetic pivalic anhydride were pumped into the column at a combined flow rate of $110 \mu \mathrm{L} / \mathrm{min}$ (residence time of $7.5 \mathrm{~min}$ ). The mixed anhydride, in turn, was prepared by combining dichloromethane solutions of $i$ - $\mathrm{Pr}_{2} \mathrm{NEt} /$ phenylacetic acid $7 \mathbf{a}$ and pivaloyl chloride and pumping the combined solution through a loop coil at a flow rate of $55 \mu \mathrm{L} / \mathrm{min}$, corresponding to a residence time of $14.2 \mathrm{~min}$. Conversion of $6 \mathrm{a}$ into $8 \mathrm{a}$ was continuously monitored by in-line FTIR, and the reaction mixture was quenched by continuous addition of water at the reactor's outlet by means of another HPLC pump (flow rate 


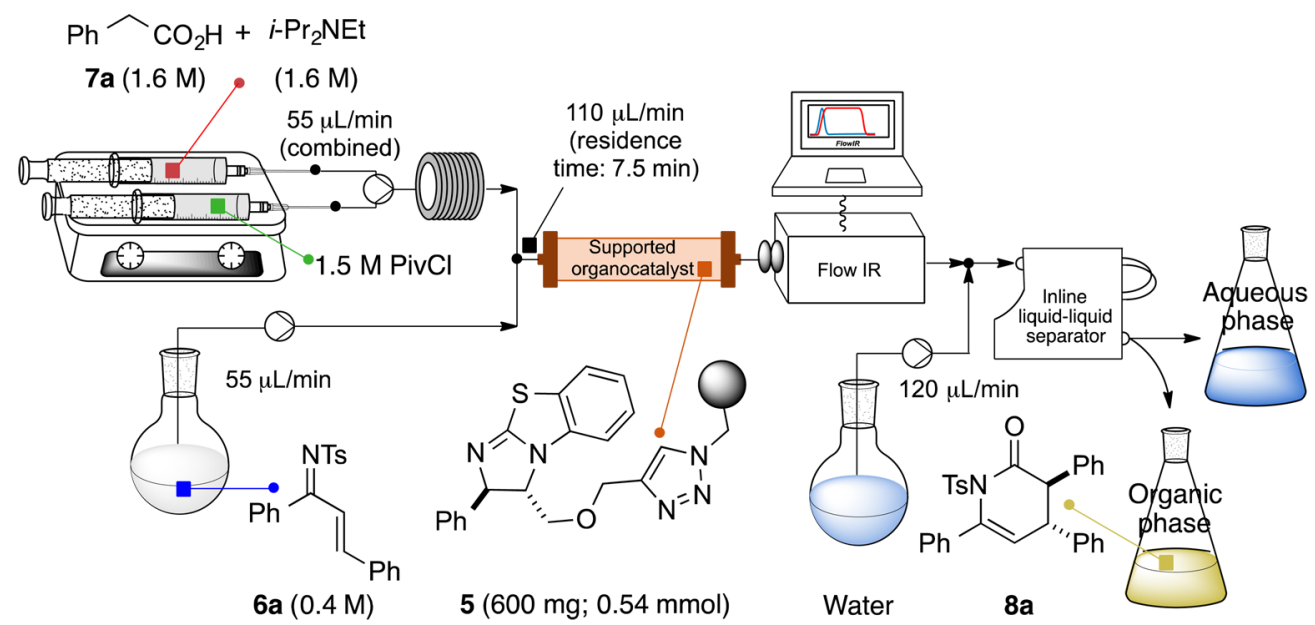

Figure 2. Continuous flow process setup for the preparation of $\mathbf{8 a}$.

Table 4. Domino Michael Addition/Cyclization of in Situ Activated Arylacetic Acids 7 with Different Saccharin-Derived Michael Acceptors 9
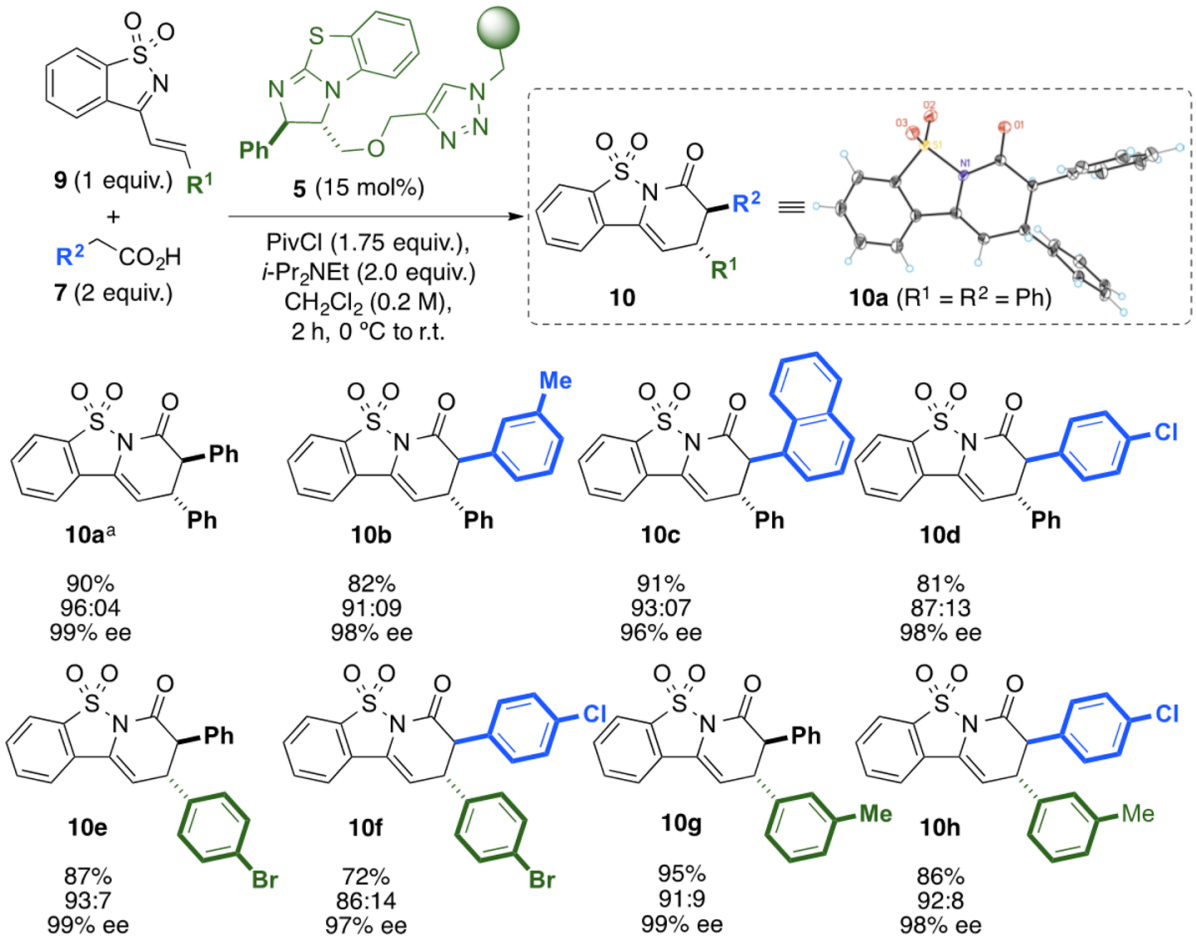

${ }^{a}$ Values under each structure are as follows: first line, isolated yield after column chromatography; second line, diastereomeric ratio determined by ${ }^{1} \mathrm{H}$ NMR; third line, enantiomeric excess determined by chiral HPLC.

$120 \mu \mathrm{L} / \mathrm{min})$. The integrated in-line liquid-liquid separator allowed the continuous collection of the dichloromethane phase, from which 8a was obtained by simple evaporation. The system was operated for $11 \mathrm{~h}$ with very high conversion and increased enantioselectivity ( $>99.9 \%$ ee) in comparison with the batch process. ${ }^{24 d}$ The material converted during the whole flow experiment represented a TON of 22.5 for the sample of immobilized catalyst used, and the amount of recrystallized 8a obtained during the experiment was $4.44 \mathrm{~g}$ (70\% yield). Further details can be found in the Supporting Information.

Supported-BTM 5 showed high activity also with cyclic sulphonylimines such as the sultams derived from saccharin (9), and we reasoned that the tricyclic derivatives 10 resulting from the domino Michael addition/cyclization reaction of these derivatives could present a possibility as drug candidates. A concise screening of the reaction with these derivatives also revealed high tolerance in the aryl substitution pattern for both substrate molecules, the reaction affording the 8,9-dihydro-7 $\mathrm{H}$ benzo[4,5]isothiazolo[2,3- $a]$ pyridin-7-one-5,5-dioxides 10 in excellent isolated yields, high diastereoselectivities, and excellent enantioselectivities (Table 4).

Next, the high catalytic activity, robustness, and recyclability of the supported BTM analogue $\mathbf{5}$ in this transformation was further demonstrated by using in a repeated manner the same sample of the immobilized catalyst for a series of experiments at the gram scale. Thus, to a $500 \mathrm{mg}(0.45 \mathrm{mmol})$ sample of resin 5 swollen in dichloromethane under argon at $0{ }^{\circ} \mathrm{C}$, were added sequentially the arylacetic acid 7 , the corresponding saccharin- 
Table 5. Sequential Preparation at the Gram Scale of a Library of Tricyclic Derivatives 10 by Domino Michael Addition/ Cyclization of in Situ Activated Arylacetic Acids 7 with Different Saccharin-Derived Michael Acceptors 9

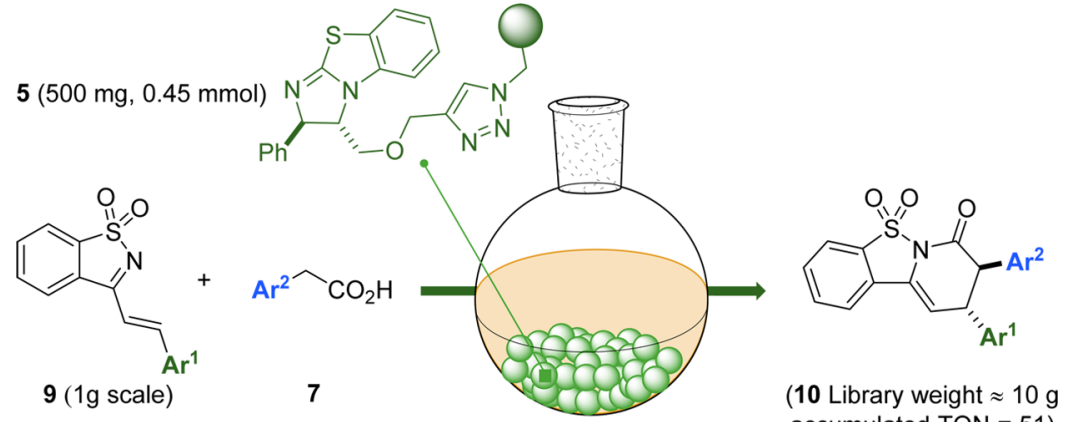
accumulated TON $=51$ )

\begin{tabular}{|c|c|c|c|c|c|c|c|}
\hline run & $\operatorname{Ar}^{1}$ & $\mathrm{Ar}^{2}$ & reaction time $(\mathrm{h})$ & product $^{a}$ (weight (g)) & yield $(\%)^{a}$ & $\mathrm{dr}^{b}$ & $\mathrm{ee}^{c}(\%)$ \\
\hline 1 & $\mathrm{Ph}$ & $\mathrm{Ph}$ & 2 & 10a $(1.35)$ & 94 & $>20: 1$ & 99 \\
\hline 2 & $\mathrm{Ph}$ & 1-naphthyl & 2 & $10 \mathrm{c}(1.33)$ & 82 & $94: 6$ & 99 \\
\hline 3 & $\mathrm{Ph}$ & $p$-chlorophenyl & 2 & $10 \mathrm{~d}(1.51)$ & 96 & $97: 3$ & 98 \\
\hline 4 & $m$-tolyl & $\mathrm{Ph}$ & 2 & $\log (1.41)$ & 95 & $94: 6$ & 97 \\
\hline 5 & $p$-bromophenyl & $\mathrm{Ph}$ & 2 & $10 \mathrm{e}(1.47)$ & 85 & $92: 8$ & 99 \\
\hline 6 & $p$-bromophenyl & $p$-chlorophenyl & 3 & $10 f(1.51)$ & 81 & $87: 13$ & 96 \\
\hline 7 & $m$-tolyl & p-chlorophenyl & 3 & 10h (1.29) & 80 & $91: 9$ & 97 \\
\hline
\end{tabular}

${ }^{a}$ Pure crystalline products. ${ }^{b} \mathrm{By}{ }^{1} \mathrm{H}$ NMR. ${ }^{c}$ By chiral HPLC.
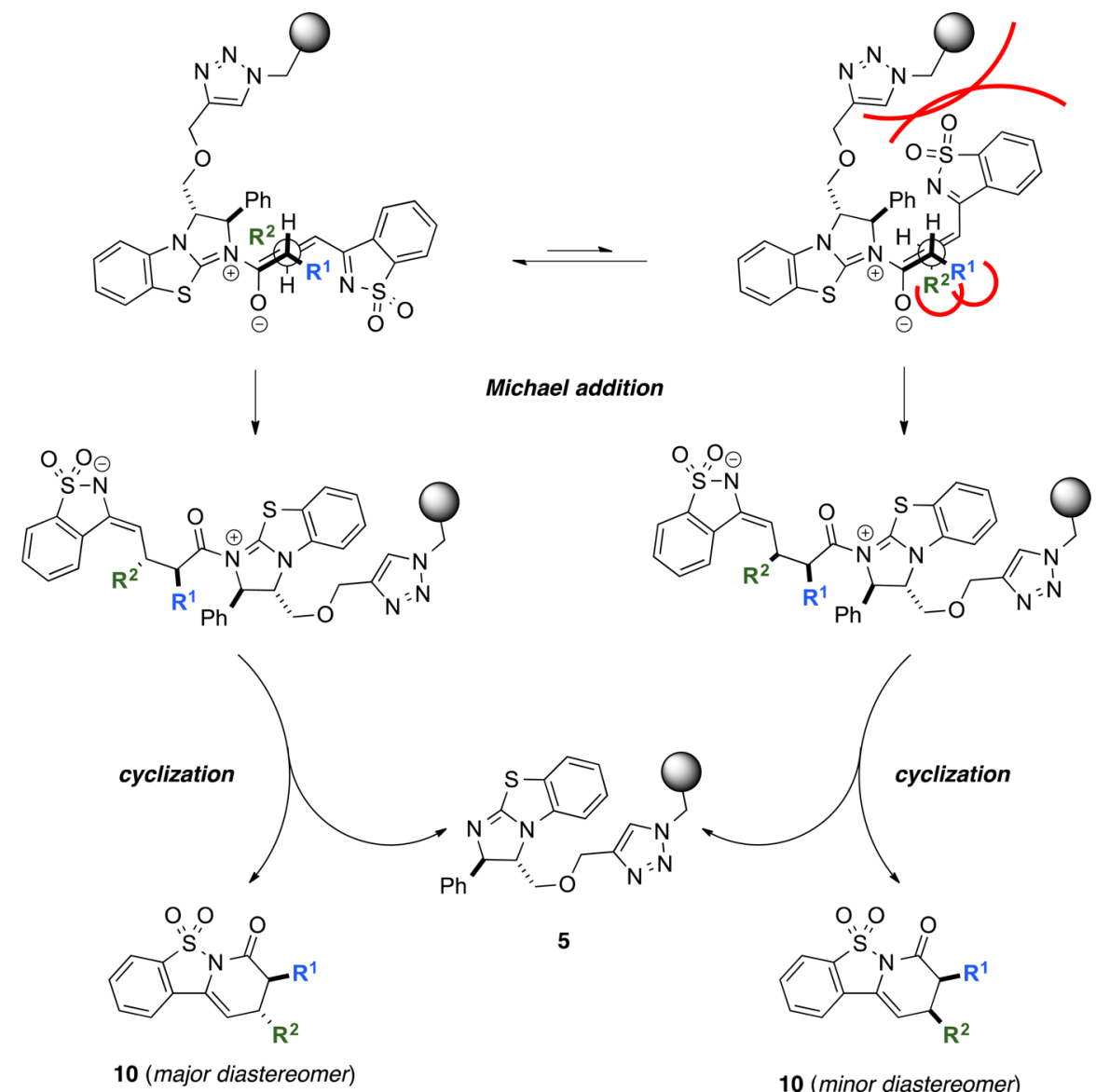

Figure 3. Rationalization of the increased diastereoselectivity in the domino Michael addition/cyclization reactions mediated by $\mathbf{5}$.

derived Michael acceptor 9, dichloromethane, $i-\mathrm{Pr}_{2} \mathrm{NEt}$, and pivaloyl chloride, and the domino Michael addition/cyclization reaction was allowed to proceed to completion while the mixture was warmed to room temperature. The reaction mixture was decanted with a syringe and the resin washed with freshly distilled dichloromethane before the addition of a new combination of reactants. Up to seven different derivatives 10 were sequentially prepared in this manner, the resin retaining most of its activity by the end of the last reaction cycle (Table 5). Almost $10 \mathrm{~g}$ (combined weight) of pure tricyclic derivatives 
Scheme 2. Preparation of $\beta$-Lactam 12 Catalyzed by Supported-BTM 5

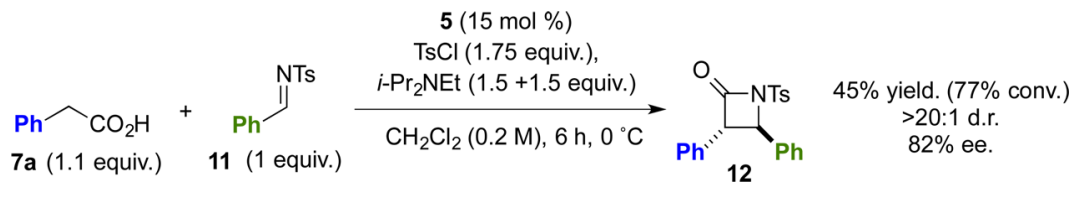

10 was isolated in these experiments, and the accumulated TON (for the employed catalyst sample) was 51. It is worth noting that the limited solubility of these products, which prevents the implementation of efficient flow processes for their preparation, allows their easy purification by simple crystallization. No column chromatography was used at all during the purification process.

From a mechanistic point of view, we assume that the catalytic cycle operating in the reactions mediated by $\mathbf{5}$ is similar to that proposed by $\operatorname{Smith}^{14 \mathrm{~b}}$ for similar reactions mediated by BTM. Thus, an acyl ammonium intermediate is formed from the in situ prepared mixed anhydride and the polystyrene-supported BTM analogue 5 . Then, the acyl ammonium species evolves into a $Z$ ammonium enolate upon deprotonation by the present tertiary amine, and the sogenerated nucleophile efficiently adds to the Michael acceptor initiating the domino process. While the configuration of the stereocenter $\alpha$ to the carbonyl group in $\mathbf{1 0}$ appears to be controlled by the phenyl substituent in the immobilized BTM analogue, as happens with the homogeneous system, the reactions mediated by 5 display improved diastereoselectivity with some substrates, as we have already mentioned. ${ }^{14 \mathrm{~b}}$ This behavior can be rationalized (Figure 3 ) by assuming that the rather bulky substituent introduced at $\mathrm{C} 3$ on the BTM molecule for immobilization purposes further destabilizes the transition state leading to the formation of the minor cis diastereomer of $\mathbf{1 0 .}$

To further expand the potential of $\mathbf{5}$ in catalysis, we have briefly examined its use in other reaction types. While its performance in the kinetic resolution of secondary alcohols ${ }^{11}$ is rather poor (see the Supporting Information), promising results have been obtained in the formation of $\beta$-lactams ${ }^{14 \mathrm{e}}$ (Scheme 2). Thus, the reaction of $7 \mathbf{a}$ with benzaldehyde $N$-tosylimine $\mathbf{1 1}$ mediated by the PS-BTM analogue 5 leads to $\beta$-lactam with diastereo- and enantioselectivities similar to those obtained with homogeneous BTM (Scheme 2).

\section{CONCLUSIONS}

In conclusion, we have developed a polystyrene-supported isothiourea organocatalyst (5) based on the BTM structure. The catalytic resin $\mathbf{5}$ can be prepared in five simple steps from readily available enantiopure phenylglycidol (arising from a catalytic Sharpless epoxidation) and displays excellent performance in the domino Michael addition/cyclization reaction of in situ activated arylacetic acids with tosylimines derived from chalcone-type enones and from saccharin. The selected immobilization strategy, involving a functional position innate to the employed synthetic approach, places the triazole linker and the polystyrene backbone away from the active site. Likewise as a result of this situation, neither the catalytic activity of $\mathbf{5}$ nor the stereoselectivity of the reactions it catalyzes suffers any decrease in comparison with homogeneous BTM. What is more, the diastereoselectivity recorded with congested arylacetic acids in the studied domino process is far superior on catalysis by $\mathbf{5}$. In addition to optimal catalytic performance, the catalytic resin $\mathbf{5}$ displays at a high level the sustainability advantages anticipated for immobilized catalysts: recyclability in batch mode, exemplified by the sequential preparation of a library of the druglike, enantiopure tricyclic derivatives $\mathbf{1 0}$ at the gram scale, and implementation of a continuous flow process for the preparation of dihydropyridinone 8a from its ultimate precursors showing substantial improvement over the corresponding batch process. Further applications of $\mathbf{5}$, the first immobilized isothiourea organocatalyst reported so far, are underway in our laboratories.

\section{ASSOCIATED CONTENT}

\section{S Supporting Information}

The Supporting Information is available free of charge on the ACS Publications website at DOI: 10.1021/acscatal.5b02121.

Experimental procedures, description of the continuous flow setup, compound and polymer characterization, NMR spectra, HPLC chromatograms, and crystallographic data for compounds 4, 8a, and 10a (PDF) Crystallographic data for compound 4 (CIF) Crystallographic data for compound 8a (CIF) Crystallographic data for compound 10a (CIF)

\section{AUTHOR INFORMATION}

\section{Corresponding Author}

*M.A.P.: e-mail, mapericas@iciq.es; fax, +34 977920244; tel, +34 977920243 .

\section{Notes}

The authors declare no competing financial interest.

\section{ACKNOWLEDGMENTS}

This work was funded by the MINECO (grant CTQ201238594-C02-01), DEC (grant 2014SGR827), and ICIQ Foundation. We also thank the MINECO for support through Severo Ochoa Excellence Accreditation 2014-2018 (SEV2013-0319). J.I. thanks the PCOFUND-GA-2011-291787 (ICIQ-IPMP) for a postdoctoral fellowship. The authors thank Mr. Shoulei Wang for experiments performed at the revision stage.

\section{REFERENCES}

(1) For general monographs, see: (a) Berkessel, A.; Gröger, H. Asymmetric Organocatalysis; Wiley-VCH: Weinheim, Germany, 2005. (b) Enantioselective Organocatalysis; Dalko, P., Ed.; Wiley-VCH: Weinheim, Germany, 2007. (c) Organocatalysis; Reetz, M. T.; List, B.; Jaroch, S.; Weinmann, H., Eds.; Springer, Berlin, Heidelberg, Germany, 2008.

(2) For some reviews on supported organocatalysts, see: (a) Benaglia, M.; Puglisi, A.; Cozzi, F. Chem. Rev. 2003, 103, 3401-3430. (b) Cozzi, F. Adv. Synth. Catal. 2006, 348, 1367-1390. (c) Kristensen, T. E.; Hansen, T. Eur. J. Org. Chem. 2010, 2010, 3179-3204. For recent reviews on flow processes involving supported organocatalysts, see: (d) Puglisi, A.; Benaglia, M.; Chiroli, V. Green Chem. 2013, 15, 17901813. (e) Rodríguez-Escrich, C.; Pericàs, M. A. Eur. J. Org. Chem. 2015, 2015, 1173-1188. (f) Atodiresei, I.; Vila, C.; Rueping, M. ACS 
Catal. 2015, 5, 1972-1985. (g) Finelli, F. G.; Miranda, L. S. M.; de Souza, R. O. M. A. Chem. Commun. 2015, 51, 3708-3722.

(3) Carey, F. A.; Sundberg, R. J. Advanced Organic Chemistry, Part B: Reactions and Synthesis; Springer; New York, 2008; pp 1-214.

(4) For a recent reference book, see: (a) The Chemistry of Metal Enolates; Zabicky, J., Ed.; Wiley: Chichester, u.K., 2009; Patai Series: The Chemistry of Functional Groups (Rappoport, Z., Series Ed.).

(5) For recent reviews involving enamine catalysis, see: (a) Mukherjee, S.; Yang, J. W.; Hoffmann, S.; List, B. Chem. Rev. 2007, 107, 5471-5569. (b) Bertelsen, S.; Jørgensen, K. A. Chem. Soc. Rev. 2009, $38,2178-2189$.

(6) For a review on isothioureas as nucleophilic catalysts, see: Taylor, J. E.; Bull, S. D.; Williams, J. M. J. Chem. Soc. Rev. 2012, 41, 21092121.

(7) For recent reviews on cinchona alkaloids as organocatalysts, see: (a) Jiang, L.; Chen, Y. C. Catal. Sci. Technol. 2011, 1, 354-365. (b) Melchiorre, P. Angew. Chem., Int. Ed. 2012, 51, 9748-9770. For a recent review on asymmetric phase transfer catalysis, see: (c) Shirakawa, S.; Maruoka, K. Angew. Chem., Int. Ed. 2013, 52, 4312-4348.

(8) For recent reviews dealing with enolate-NHC generation and reactivity, see: (a) Vora, H. U.; Wheeler, P.; Rovis, T. Adv. Synth. Catal. 2012, 354, 1617-1639. (b) Ryan, S. J.; Candish, L.; Lupton, D. W. Chem. Soc. Rev. 2013, 42, 4906-4917. (c) Hopkinson, M. N.; Richter, C.; Schedler, M.; Glorius, F. Nature 2014, 510, 485-496. (d) Flanigan, D. M.; Romanov-Michailidis, F.; White, N. A.; Rovis, T. Chem. Rev. 2015, 115, 9307.

(9) For a general review involving ammonium enolates, see: Gaunt, M. J.; Johansson, C. C. C. Chem. Rev. 2007, 107, 5596-5605.

(10) For a review on organocatalytic Lewis base functionalization of carboxylic acids via ammonium enolates, see: (a) Morrill, M. C.; Smith, A. D. Chem. Soc. Rev. 2014, 43, 6214-6226. For recent examples, see: (b) Lee, A.; Younai, A.; Price, C. K.; Izquierdo, J.; Mishra, R. K.; Scheidt, K. A. J. Am. Chem. Soc. 2014, 136, 1058910592. (c) Chen, X. Y.; Gao, Z. H.; Song, C. Y.; Zhang, C. L.; Wang, Z. X.; Ye, S. Angew. Chem., Int. Ed. 2014, 53, 11611-11615. (d) Cheng, J. T.; Chen, X. Y.; Ye, S. Org. Biomol. Chem. 2015, 13, 1313-1316. (e) Xie, Y.; Yu, C.; Li, T.; Tu, S.; Yao, C. Chem. - Eur. J. 2015, 21, 5355-5359. (f) Jin, Z.; Jiang, K.; Fu, Z.; Torres, J.; Zheng, P.; Yang, S.; Song, B. A.; Chi, Y. R. Chem. - Eur. J. 2015, 21, 93609363.

(11) Birman, V. B.; Li, X. Org. Lett. 2006, 8, 1351-1354.

(12) (a) Birman, V. B.; Guo, L. Org. Lett. 2006, 8, 4859-4861. (b) Birman, V. B.; Jiang, H.; Li, X.; Guo, L.; Uffman, E. W. J. Am. Chem. Soc. 2006, 128, 6536-6537. (c) Birman, V. B.; Jiang, H.; Li, X. Org. Lett. 2007, 9, 3237-3240. (d) Yang, X.; Lu, G.; Birman, V. B. Org. Lett. 2010, 12, 892-895. (e) Bumbu, V. D.; Birman, V. B. J. Am. Chem. Soc. 2011, 133, 13902-13905. (f) Li, X.; Jiang, H.; Uffman, E. W.; Guo, L.; Zhang, Y.; Yang, X.; Birman, V. B. J. Org. Chem. 2012, 77, 1722-1737. (g) Yang, X.; Bumbu, V. D.; Liu, P.; Li, X.; Jiang, H.; Uffman, E. W.; Guo, L.; Zhang, W.; Jiang, X.; Houk, K. N.; Birman, V. B. J. Am. Chem. Soc. 2012, 134, 17605-17612. (h) Bumbu, V. D.; Yang, X.; Birman, V. B. Org. Lett. 2013, 15, 2790-2793.

(13) (a) Purohit, V. C.; Matla, A. S.; Romo, D. J. Am. Chem. Soc. 2008, 130, 10478-10479. (b) Leverett, C.; Purohit, V. C.; Romo, D. Angew. Chem., Int. Ed. 2010, 49, 9479-9483. (c) Leverett, C. A.; Purohit, V. C.; Johnson, A. G.; Davis, R. L.; Tantillo, D. J.; Romo, D. J. Am. Chem. Soc. 2012, 134, 13348-13356. (d) Liu, G.; Shirley, M. E.; Van, K. N.; McFarlin, R. L.; Romo, D. Nat. Chem. 2013, 5, 10491057.

(14) (a) Belmessieri, D.; Morrill, L. C.; Simal, C.; Slawin, A. M. Z.; Smith, A. S. J. Am. Chem. Soc. 2011, 133, 2714-2720. (b) Simal, C.; Lebl, T.; Slawin, A. M. Z.; Smith, A. D. Angew. Chem., Int. Ed. 2012, 51, 3653-3657. (c) Morrill, L. C.; Douglas, J.; Lebl, T.; Slawin, A.M. Z.; Fox, D. J.; Smith, A. D. Chem. Sci. 2013, 4, 4146-4155. (d) Morrill, L. C.; Stark, D. G.; Taylor, J. E.; Smith, S. R.; Squires, J. A.; D’Hollander, A. C. A.; Simal, C.; Shapland, P.; O’Riordanc, T. J. C.; Smith, A. D. Org. Biomol. Chem. 2014, 12, 9016-9027. (e) Smith, R. S.; Douglas, J.; Prevet, H.; Shapland, P.; Slawin, A. M. Z.; Smith, A. D. J. Org. Chem. 2014, 79, 1626-1639. (f) Morrill, L. C.; Smith, S. M.; Slawin, A. M.
Z.; Smith, A. D. J. Org. Chem. 2014, 79, 1640-1655. (g) Smith, S. R; Leckie, S. M.; Holmes, R.; Douglas, J.; Fallan, C.; Shapland, P.; Pryde, D.; Slawin, A. M. Z.; Smith, A. D. Org. Lett. 2014, 16, 2506-2509. (h) Morrill, L. C.; Ledingham, L. A.; Couturier, J. P.; Bickel, J.; Harper, A. D.; Fallan, C.; Smith, A. D. Org. Biomol. Chem. 2014, 12, 624-636. (i) Yeh, P. P.; Daniels, D. S. B.; Fallan, C.; Gould, E.; Simal, C.; Taylor, J. E.; Slawin, A. M. Z.; Smith, A. Org. Biomol. Chem. 2015, 13, 21772191.

(15) (a) Nantermet, P. G.; Barrow, J. C.; Selnick, H. G.; Homnick, C. F.; Freidinger, R. M.; Chang, R. S. L.; O’Malley, S. S.; Reiss, D. R.; Broten, T. P.; Ransom, R. W.; Pettibone, D. J.; Olah, T.; Forray, C. Bioorg. Med. Chem. Lett. 2000, 10, 1625-1628. (b) Goodman, K. B.; Cui, H.; Dowdell, S. E.; Gaitanopoulos, D. E.; Ivy, R. L.; Sehon, C. A.; Stavenger, R. A.; Wang, G. Z.; Viet, A. Q.; Xu, W.; Ye, G.; Semus, S. F.; Evans, C.; Fries, H. E.; Jolivette, L. J.; Kirkpatrick, R. B.; Dul, E.; Khandekar, S. S.; Yi, T.; Jung, D. K.; Wright, L. L.; Smith, G. K.; Behm, D. J.; Bentley, R.; Doe, C. P.; Hu, E.; Lee, D. J. Med. Chem. 2007, 50, 6-9. (c) Dinakaran, M.; Senthilkumar, P.; Yogeeswari, P.; China, A.; Nagaraja, V.; Sriram, D. Bioorg. Med. Chem. 2008, 16, 3408-3418. (d) Haddach, M.; Schwaebe, M. K.; Michaux, J.; Nagasawa, J.; O’Brien, S. E.; Whitten, J. P.; Pierre, F.; Kerdoncuff, P.; Darjania, L.; Stansfield, R.; Drygin, D.; Anderes, K.; Proffitt, C.; Bliesath, J.; Siddiqui-Jain, A.; Omori, M.; Huser, N.; Rice, W. G.; Ryckman, D. M. ACS Med. Chem. Lett. 2012, 3, 602-606.

(16) (a) Boger, D. L.; Kasper, A. M. J. Am. Chem. Soc. 1989, 111, 1517-1519. For reviews, see: (b) Behforouz, M.; Ahmadian, M. Tetrahedron 2000, 56, 5259-5288. (c) Jayakumar, S.; Ishar, M. P. S.; Mahajan, M. P. Tetrahedron 2002, 58, 379-471. (d) Weintraub, P. M.; Sabol, J. S.; Kane, J. M.; Borcherding, D. R. Tetrahedron 2003, 59, 2953-2989. (e) Groenendaal, B.; Ruijter, E.; Orru, R. V. A. Chem. Commun. 2008, 5474-5489.

(17) Esquivias, J.; Gómez-Arrayás, R.; Carretero, J. C. J. Am. Chem. Soc. 2007, 129, 1480-1481.

(18) (a) Han, B.; Li, J. L.; Ma, C.; Zhang, S. J.; Chen, Y. C. Angew. Chem., Int. Ed. 2008, 47, 9971-9974. (b) Han, B.; He, Z. Q.; Li, J. L.; Li, R.; Jiang, K.; Liu, T. Y.; Chen, Y. C. Angew. Chem., Int. Ed. 2009, 48, 5474-5477. (c) Gu, J.; Ma, C.; Li, Q. Z.; Du, W.; Chen, Y. C. Org. Lett. 2014, 16, 3986-3989. (d) An, Q.; Shen, J.; Butt, N.; Liu, D.; Liu, Y.; Zhang, W. Org. Lett. 2014, 16, 4496-4499. (e) An, Q.; Li, J.; Shen, J.; Butt, N.; Liu, D.; Liu, Y.; Zhang, W. Chem. Commun. 2015, 51, $885-888$.

(19) (a) He, M.; Struble, J. R.; Bode, J. W. J. Am. Chem. Soc. 2006, 128, 8418-8420. (b) Jian, T. Y.; Shao, P. L.; Ye, S. Chem. Commun. 2011, 47, 2381-2383. (c) Hao, L.; Du, Y.; Lv, H.; Chen, X.; Jiang, H.; Shao, Y.; Chi, Y. R. Org. Lett. 2012, 14, 2154-2157. (d) Jian, T. Y.; Sun, L. H.; Ye, S. Chem. Commun. 2012, 48, 10907-10909. (e) Kravina, A. G.; Mahatthananchai, J.; Bode, J. W. Angew. Chem., Int. Ed. 2012, 51, 9433-9436. (f) Zhao, X.; Ruhl, K. E.; Rovis, T. Angew. Chem., Int. Ed. 2012, 51, 12330-12333. (g) Hao, L.; Chuen, C. W.; Ganguly, R.; Chi, Y. R. Synlett 2013, 24, 1197-1200. (h) Hao, L.; Chen, S.; Xu, J.; Tiwari, B.; Fu, Z.; Li, T.; Lim, J.; Chi, Y. R. Org. Lett. 2013, 15, 4956-4959. (i) Cheng, J.; Huang, Z.; Chi, Y. R. Angew. Chem., Int. Ed. 2013, 52, 8592-8596. (j) Fu, Z.; Jiang, K.; Zhu, T.; Torres, J.; Chi, Y. R. Angew. Chem., Int. Ed. 2014, 53, 6506-6510. (k) Ni, Q.; Song, X.; Xiong, J.; Raabe, G.; Enders, D. Chem. Commun. 2015, 51, 1263-1266. (l) Ni, Q.; Xiong, J.; Song, X.; Raabe, G.; Enders, D. Synlett 2015, 26, 1465-1469. (m) Song, X.; Ni, Q.; Zhu, C.; Raabe, G.; Enders, D. Synthesis 2015, 47, 421-428. (n) Gao, Z. H.; Chen, X. Y.; Zhang, H. M.; Ye, S. Chem. Commun. 2015, 51, 1204012043.

(20) (a) Katsuki, T.; Sharpless, K. B. J. Am. Chem. Soc. 1980, 102, 5974-5976. (b) Gao, Y.; Hanson, R. M.; Klunder, J. M.; Ko, S. Y.; Masamune, H.; Sharpless, K. B. J. Am. Chem. Soc. 1987, 109, 57655780.

(21) For previous examples from this laboratory on the use of catalytically prepared, enantiopure epoxides as starting materials for the preparation of ligands and organocatalysts in view of immobilization, see: (a) Vidal-Ferran, A.; Bampos, N.; Moyano, A.; Pericàs, M. A.; Riera, A.; Sanders, J. K. M. J. Org. Chem. 1998, 63, 
6309-6318. (b) Pericàs, M. A.; Castellnou, D.; Rodríguez, I.; Riera, A.; Solà, L. Adv. Synth. Catal. 2003, 345, 1305-1313. (c) Castellnou, D.; Sola, L.; Jimeno, C.; Fraile, J. M.; Mayoral, J. A.; Riera, A.; Pericàs, M. A. J. Org. Chem. 2005, 70, 433-438. (d) Bastero, A.; Font, D.; Pericàs, M. A. J. Org. Chem. 2007, 72, 2460-2468. (e) Popa, D.; Marcos, R.; Sayalero, S.; Vidal-Ferran, A.; Pericàs, M. A. Adv. Synth. Catal. 2009, 351, 1539-1556. (f) Martín-Rapún, R.; Sayalero, S.; Pericàs, M. A. Green Chem. 2013, 15, 3295-3301.

(22) (a) Rostovtsev, V. V.; Green, L. G.; Fokin, V. V.; Sharpless, K. B. Angew. Chem., Int. Ed. 2002, 41, 2596-2599. (b) Tornøe, C. W.; Christensen, C.; Meldal, M. J. Org. Chem. 2002, 67, 3057-3064.

(23) Kolb, H. C.; Finn, M. G.; Sharpless, K. B. Angew. Chem., Int. Ed. 2001, 40, 2004-2021.

(24) For a review of application of CuAAC for the immobilization of homogeneous catalysts, see: (a) Fernandes, A. E.; Jonas, A. M.; Riant, O. Tetrahedron 2014, 70, 1709-1731. For recent successful examples from our laboratory involving $\mathrm{CuAAC}$ for immobilizing catalysts, see: (b) Henseler, A. H.; Ayats, C.; Pericàs, M. A. Adv. Synth. Catal. 2014, 356, 1795-1802. (c) Ayats, C.; Henseler, A. H.; Dibello, E.; Pericàs, M. A. ACS Catal. 2014, 4, 3027-3033. (d) Izquierdo, J.; Ayats, C.; Henseler, A. H.; Pericàs, M. A. Org. Biomol. Chem. 2015, 13, 42044209.

(25) (a) Popa, D.; Marcos, R.; Sayalero, S.; Vidal-Ferrán, V.; Pericàs, M. A. Adv. Synth. Catal. 2009, 351, 1539-1556. (b) Sau, M.; Rodríguez-Escrich, C.; Pericàs, M. A. Org. Lett. 2011, 13, 5044-5047.

(26) Pastó, M.; Rodríguez, B.; Riera, A.; Pericàs, M. A. Tetrahedron Lett. 2003, 44, 8369-8372.

(27) Crystal data are provided in the Supporting Information.

(28) Fukata, Y.; Asano, K.; Matsubara, S. J. Am. Chem. Soc. 2015, 137, $5320-5323$.

(29) $\alpha, \alpha$-Diphenylacetic acid, $\alpha$-methyl- $\alpha$-phenylacetic acid, propionic acid, and dihydrocinnamic acid did not afford any desired product. 